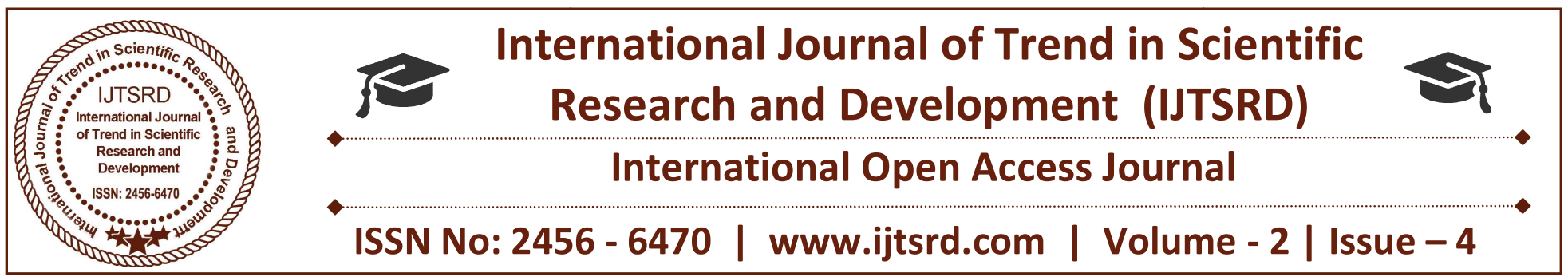

\title{
A Study on Mobile Learning and its Impact on Academic Achievement among Higher Secondary Commerce Students
}

\author{
Ms. A. Masilamani ${ }^{1}$, Mr. S. Mahendren ${ }^{2}$ \\ ${ }^{1}$ M. Ed Student, ${ }^{2}$ Assistant Professor in Pedagogy of History \\ RVS College of Education, Coimbatore, Tamil Nadu, India
}

\begin{abstract}
The present study aimed to examine the effect of Mobile Learning, which is a kind of E learning that uses mobile devices, on the development of the academic achievement of higher secondary commerce students at Coimbatore, Tamilnadu. The study used the quasi-experimental approach. Participants consisted of (712) students who were registered in a group called Commerce offered by the Tamilnadu stateboard. The questionnaires were givent to students in the experimental group. Data collection tools included an academic achievement test and feedback rating scale. Results showed that mobile learning had quite significant effect on both students' academic achievement and conversational skills. In light of these findings faculty members were recommended to adapt the use of Mobile Learning in their classes.
\end{abstract}

\section{INTRODUCTION}

In the present day, higher educational institutions throughout the world are increasingly being persuaded to make use of mobile technology a trend that is widely accepted and used almost everywhere in the world as a mode of communication. The fastpaced evolution of emerging technologies in this area has a significant effect on the way society communicates, learns, accesses information, and connects with peers and colleagues. The pervasive nature and application of innovative technologies continue to challenge the foundations of learning, teaching, research, and creative inquiry, especially in the higher education arena. This emerging 21 st century mobility paradigm presents opportunities, challenges, and, sometimes, barriers in the ways learners interact, collaborate, connect, contextualize, and personalize their learning environments. Therefore, the field of mobile learning
(mLearning) is becoming increasingly capable of supporting high quality learning experiences. On top of this, students are increasingly demanding greater mobility and flexibility in their learning experiences. As a result, higher education has been gradually considering the implementation of institutional $\mathrm{m}$ Learning strategies. Furthermore, researchers have come to appreciate that mobile technology has facilitated intercommunication in ways that were never thought of before. Thus, it is generally accepted that the concept of mLearning is much wider in scope than simply gaining or imparting knowledge using mobile technology, and that mLearning involves related investigations into how interpersonal interactions using mobile technology can facilitate the process of learning. Moreover, the rapid development in mobile technology has correspondingly increased capabilities in supporting education not only in standalone environments but also in blended contexts, i.e., in conjunction with traditional teaching techniques. This has made the field of mLearning into the new learning paradigm. The field is now the focus of increasing research and development (R\&D) activities.

MLearning is a fairly recent concept and research in this area is still in its infancy. In fact, the earliest research projects in this field started appearing only in the latter half of the 1990s and the first international research conference dates back less than a decade. As is obvious, the relative newness of the field also means that the processes, frameworks, tools, etc., have not yet been standardized The continually evolving concepts in mLearning, related to both technology and communication networking, makes 
the research into mLearning challenging in every aspect including evaluation. In order to overcome the challenges of evaluation, tailored tools and frameworks need to be developed. Presently, researchers in this field borrow frameworks and tools from other areas based on their similarities. However, these practices will not be sufficient if the acceptance of the technology is to be popular and universal.

The continually evolving concepts in mLearning, related to both technology and communication networking, makes the research into mLearning challenging in every aspect including evaluation. In order to overcome the challenges of evaluation, tailored tools and frameworks need to be developed. Presently, researchers in this field borrow frameworks and tools from other areas based on their similarities. However, these practices will not be sufficient if the acceptance of the technology is to be popular and universal. In order to successfully use the full capabilities of mobile technology in the educational sector, the assessment framework would have to include these contexts. Thus it can be seen that existing frameworks for educational evaluation, including for platforms such as eLearning, are not sufficient for successfully evaluating mLearning. This points to a clear need for developing assessment frameworks that are especially tailored to assess mLearning and its successful implementation in the educational sector.

\section{REVIEW OF LITERATURE}

Nikou, S. A. , and A. A. Economides. (2018) studied uses the lens of the Self determination Theory of motivation and proposes a series of MobileBased micro Learning and Assessment (MBmLA) homework activities to improve high school students motivation and learning performance in science. An experiment was conducted to evaluate the effectiveness of the proposed approach. One hundred and eight students of a senior level high school in Europe were randomly assigned into either a control condition (conventional paperbased homework approach) or an experimental (MBmLA approach) condition. The study carried out for a period of 5 weeks. From the experimental results, it was found that, in comparison to the conventional paper based approach, the proposed MBmLA approach enhanced students basic psychological needs of self perceived autonomy, competence, and relatedness and improved students exam performance in terms of factual knowledge. Reeves, Jennifer L., Glenda A. Gunter, and Candace Lacey (2017) research has focused on creating student collaborative efforts and increasing engagement when learning using the iPad, as well as the user-friendly characteristics and the tremendous number of apps available. There continues to be a need for empirical evidence supporting the effectiveness of mobile devices on student achievement. The purpose of this study was to determine how integrating mobile devices into a PreKindergarten curriculum using informal feedback from students affects students academic achievement. The study employed a twogroup, quasiexperimental design consisting of 28 students from two PreK classrooms. The experimental group utilized iPads with guided instruction, coupled with informal feedback from students, to target emergent literacy and early math skills; the control group did not have access to iPads. All students were given the Florida VPK Assessment at the beginning and end of the study. Results of the ANCOVA revealed significantly higher Phonological Awareness and Mathematics measures for the iPad class, suggesting that integrating mobile learning in content specific areas using informal student feedback effectively increases early childhood education students academic achievement.

I Boticki and J Baksa (2015) examined SamEx, a mobile learning system used by 305 students in formal and informal learning in a primary school in Singapore. Students use SamEx in situ to capture media such as pictures, video clips and audio recordings, comment on them, and share them with their peers. Their research shows that the quantity and quality of contributions provided by the students in SamEx predict the end year assessment score. With respect to specific system features, contextual answers given by the students and the overall likes received by students are also correlated with the endyear assessment score. Baran, Evrim. (2014) presented qualitative synthesis of quantitative and qualitative research aimed to address trends and gaps observed in the literature regarding the integration of mobile learning into teacher education. Six main findings emerged: (a) there is an increasing trend in integrating mobile learning in teacher education contexts; (b) theoretical and conceptual perspectives are scarcely reported; (c) variations exist in perceptions, attitudes and usage patterns; (d) engagement with mobile learning and devices is primarily reported as being beneficial; (e) challenges were scarcely reported; and (f) several pedagogical affordances support mobile learning integration into teacher education settings. 
These findings have been interpreted to determine their implications on the development of mobile learning experiences in teacher education, including programmatic directions for integration and study. Traxler, John (2009) explains start of the current millennium, experience and expertise in the development and delivery of mobile learning have blossomed and a community of practice has evolved that is distinct from the established communities of tethered elearning. This community is currently visible mainly through dedicated international conference series, of which MLEARN is the most prestigious, rather than through any dedicated journals. So far, these forms of development and delivery have focused on shortterm smallscale pilots and trials in the developed countries of Europe, North America, and the Pacific Rim, and there is a taxonomy emerging from these pilots and trials that suggests tacit and pragmatic conceptualizations of mobile learning. What has, however, developed less confidently within this community is any theoretical conceptualization of mobile learning and with it any evaluation methodologies specifically aligned to the unique attributes of mobile learning. Some advocates of mobile learning attempt to define and conceptualize it in terms of devices and technologies; other advocates do so in terms of the mobility of learners and the mobility of learning, and in terms of the learners experience of learning with mobile devices. Laouris, Yiannis, and Nikleia Eteokleous (2005) challenges current definitions of mobile learning and suggest that the direction of progress, both in theoretical/applied research as well as its role as a tool that serves social transformation and development, will be determined and even dictated by the availability of an adequate definition. A new framework for the definition of mobile learning is proposed, one that considers a repertoire of domains, and which embraces not only technical, methodological and educational aspects, but also considers social and philosophical dimensions. I Boticki and J Baksa (2002) convergences of mobile communications and handheld computers offers the opportunity to develop technology that will assist individuals and groups to learn anytime, anywhere. We describe the theory informed design, implementation and evaluation of a handheld learning device. It is intended to support children to capture everyday events such as images, notes and sounds, to relate them to web based learning resources, to organise these into a visual knowledge map, and to share them with other learners and teachers. A working prototype system, for children aged 911, is discussed and evaluated, as an exemplar of personal mobile systems for lifelong learning. It has shown that a handheld or wearable device, with appropriate learning tools and resources.

Nedungadi, Prema, Karunya Mulki, and Raghu Raman (2018) developed reduction of teacher and student absenteeism, together with consistent teacher support and training, are critical factors in improving the quality of education in rural India. As part of an ongoing project involving schools and educational centers in rural areas spread across 21 Indian states, this study investigated how implementation of two simple, accessible technologies could not only reduce absenteeism but also increase teachers effectiveness and improve student performance. In addition to students and teachers, key stakeholders included educational coordinators who provided support and monitoring regarding use of WhatsApp and two additional apps designed specifically to support simple educational improvements. In our study we coded and analyzed nine months of messages $(n=8968)$, both photographs and texts, posted by 26 participants. The number of text messages related to attendance was strongly positively correlated with frequency of interactions between coordinators and teachers. Our approach resulted in increased teacher and student attendance, as well as improvements in lessons and other planned educational activities. This model functions well in rural settings where there is poor internet connectivity and lack of supporting infrastructure. Remote schools can easily adopt this tabletbased model to reduce teacher absenteeism, improve teaching techniques, improve educational resources, and increase student performance. Karthikeyan, P., K. V. Uma, and S. Pudumalar (2015) provides a quantitative survey of different learners on effectiveness of mobile learning at Thiagarajar College of Engineering (TCE), Madurai, India. The objective of this survey is to incorporate mobile learning in complex subjects for obtaining high level knowledge among the various types of student learners at TCE.

Agarwal, Anmol, et al (2014) studied the rapid development of mobile devices, augmented reality has extended from personal computers to mobile devices. They are getting popular as a platform for Augmented Reality (AR) application such as a Smartphone. The highly interactive nature of augmented reality with its user has given rise to various augmented reality applications for mobile devices, ranging from mere 
interaction to marketing, games, navigation, and so on. Mobile AR is mainly available whenever people require an informational support for a focused task. The objectives of the proposed work include main aspects of Augmented Reality (AR) for development of mobile applications. It describes the main fields in which mobile applications are developed using AR devices \& systems. A mobile platform implementing the described features and collaboration between mobile and augmented reality is being demonstrated.

\section{OBJECTIVES OF THE STUDY}

1. To study the impact of mobile learning on academic achievement among higher secondary commerce students.

2. To develop a questionnaire to assess the impact of mobile learning on achievement among higher secondary commerce students

3. To find out the impact of mobile learning among higher secondary commerce students.

4. To find out the impact of mobile learning among higher secondary commerce students with respect to gender.

5. To find out the impact of mobile learning among higher secondary commerce students with respect to medium of instruction.

6. To find out the impact of mobile learning among higher secondary commerce students with respect to school type.

7. To find out the impact of mobile learning among higher secondary commerce students with respect to school location.

\section{RESEARCH QUESTIONS}

1. Is there any significance mean score difference between Gender and impact of mobile learning among higher secondary commerce students?

2. Is there any significance mean score difference between medium of instruction related factors and impact of mobile learning among higher secondary commerce students?

3. Is there any significance mean score difference between school type related factors and impact of mobile learning among higher secondary commerce students?

4. Is there any significance mean score difference between school location and impact of mobile learning among higher secondary commerce students?

\section{HYPOTHESES}

1. There will be a significant mean score difference between gender and impact of mobile learning among higher secondary commerce students.

2. There will be a significant mean score difference between medium of instruction related factors and impact of mobile learning among higher secondary commerce students.

3. There will be a significant mean score difference between school type related factors and impact of mobile learning among higher secondary commerce students.

4. There will be a significant mean score difference between school location and impact of mobile learning among higher secondary commerce students.

\section{VARIABLES}

An independent variable is a variable that is expected to influence the dependent variables. Its value may be changed or altered, which is independent of any other variables. Also the following demographic variables were used as independent variables.

Gender (Male/Female).

Medium of instruction (Tamil/English).

School Type (Government/Private).

School Location (Urban/Rural).

Dependent variable are those events which are by hypothesized as dependent on the changes in the dependent variable (Impact on academic achievement among higher secondary commerce students).

\section{DESIGN OF THE STUDY}

In the presence study Normative survey method will be adopted. Survey research employee questioner and interview to our people who provide informations about them selfs their attitude and believes demographic (Age, Gender, Income and So on) the survey method can be classified into many,but according to the objectives and hypotheses in this presence study normative survey method will be adopted.

\section{POPULATION AND SAMPLE}

Coimbatore district is one of the district in Tamilnadu, India. Coimbatore is finest education district of Tamilnadu. It is the second largest city in Tamilnadu and one of the fastest growing cities in Tamilnadu State.For the present study the investigator select only 6 Schools from both Government and Private School around Coimbatore. Investigator selected 
Datas will be collected from the samples of 712 Students of various schools.

\section{SAMPLING TECHNIQUES}

Sampling procedure is a definite plan determined before any data are actually collected for obtaining a sample from a given population under the simple random sampling technique. This sampling method is used for selecting samples. Simple random sampling is method in which each and every element in the population has an equal chance of getting selected. The study is based on primary data which is collected from 712 school students at higher secondary level and around Coimbatore district. The sample which was collected from various college located in and around Coimbatore is shown as below.

Table 1.1 List of schools used for data collection

\begin{tabular}{|l|l|l|}
\hline $\begin{array}{l}\text { S. } \\
\text { No. }\end{array}$ & Name of the schools & $\begin{array}{l}\text { Number } \\
\text { of } \\
\text { students }\end{array}$ \\
\hline 1 & $\begin{array}{l}\text { Kennedy Matriculation Higher } \\
\text { Secondary School, Sulur }\end{array}$ & 44 \\
\hline 2 & $\begin{array}{l}\text { Sri Ramaswamy Naidu } \\
\text { Vidyalayam Higher Secondary } \\
\text { School, Sulur }\end{array}$ & 47 \\
\hline 3 & $\begin{array}{l}\text { Michael Job Matriculation Higher } \\
\text { Secondary School, Sulur, }\end{array}$ & 48 \\
\hline 4 & $\begin{array}{l}\text { Government Boys Higher } \\
\text { secondary School, Sulur }\end{array}$ & 56 \\
\hline 5 & $\begin{array}{l}\text { Government Girls Higher } \\
\text { secondary School, Sulur }\end{array}$ & 50 \\
\hline 6 & $\begin{array}{l}\text { Government Higher Secondary } \\
\text { School Irugur }\end{array}$ & 55 \\
\hline
\end{tabular}

TABLE 1.2 Distribution of Samples Based on Variables

\begin{tabular}{|l|l|l|l|l|}
\hline Category & Subgroups & Number & $\%$ & Total \\
\hline \multirow{3}{*}{ Gender } & Male & 160 & 53.23 & 300 \\
\cline { 2 - 5 } & Female & 140 & 46.77 & \\
\hline \multirow{2}{*}{$\begin{array}{l}\text { Medium } \\
\text { Instruction }\end{array}$} & Tamil & 208 & 69.38 & \multirow{2}{*}{300} \\
\cline { 2 - 5 } $\begin{array}{l}\text { School } \\
\text { Type }\end{array}$ & English & 92 & 30.62 & \\
\cline { 2 - 4 } $\begin{array}{l}\text { School } \\
\text { Location }\end{array}$ & Private & 161 & 53.65 & \multirow{2}{*}{300} \\
\cline { 2 - 5 } & Rural & 131 & 46.35 & \\
\hline \multirow{2}{*}{ urban } & 197 & 34.27 & 300 \\
\hline
\end{tabular}

\section{RESEARCH TOOL}

Tool becomes another major consideration in an education research. The instrument employed for the collection of data required for the study of any problem is called tool. Tool employ distinction way of describing and qualifying the data the important tools of educational research include interview schedule, questionnaire observation, rating scale, proficiency test, psychological tests and sociogram.

\section{TESTING HYPOTHESIS 1:}

There will be a significant mean score difference in impact of mobile learning among higher secondary commerce students academic achievement based on gender (Male/Female).

TABLE 1.3 Mean Score difference and t- value of factors related to impact of mobile learning among higher secondary commerce students academic achievement based on gender

\begin{tabular}{|l|l|l|l|l|l|l|}
\hline $\begin{array}{l}\text { S. } \\
\text { No. }\end{array}$ & Gender & N & Mean & Df & $\begin{array}{l}\text { T- } \\
\text { Value }\end{array}$ & Result \\
\hline 1 & Male & 160 & 1.2856 & 299 & 2.087 & $\mathrm{~S}$ \\
\hline 2 & Female & 140 & 1.2109 & & & \\
\hline \multicolumn{2}{|l|}{ Total } & 300 & 1.2483 & & & \\
\hline
\end{tabular}

The Table 1.3 shows the mean score difference in impact of mobile learning among higher secondary commerce students academic achievement based on gender (Male/Female).The calculate $t$ value is statistically a significance at 0.05 levels and hence the hypotheses 1 is accepted. It can be concluded that there is a significant difference in mean score difference in impact of mobile learning among higher secondary commerce students academic achievement based on gender.

\section{FEMALE : 1.2109}

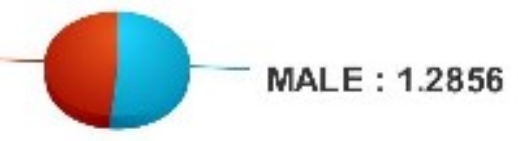

Figure 1: Relationship Between Students Gender and Impact of Mobile Learning Among Higher Secondary Commerce Students Academic Achievement

\section{TESTING HYPOTHESIS 2:}

There will be a significant mean score difference in impact of mobile learning among higher secondary commerce students academic achievement based on Medium of instruction (Tamil/English). 
TABLE 1.4 Mean Score difference and t- value of factors related to impact of mobile learning among higher secondary commerce students academic achievement based on Medium of instruction (Tamil/English).

\begin{tabular}{|l|l|l|l|l|l|l|}
\hline $\begin{array}{l}\text { S. } \\
\text { No. }\end{array}$ & Medium & $\mathrm{N}$ & Mean & Df & $\begin{array}{l}\text { T- } \\
\text { Value }\end{array}$ & Result \\
\hline 1 & Tamil & 208 & 1.1975 & & & \\
\cline { 1 - 4 } 2 & English & 92 & 1.2135 & 299 & -2.897 & $\mathrm{~S}$ \\
\hline \multicolumn{2}{|l|}{ Total } & 300 & 1.2055 & & & \\
\hline
\end{tabular}

The Table 1.4 shows the mean score difference in impact of mobile learning among higher secondary commerce students academic achievement based on Medium of Instruction (Tamil/English). The calculate t value is statistically a significance at 0.05 levels and hence the hypotheses 2 is accepted. It can be concluded that there is a significant difference in mean score difference in impact of mobile learning among higher secondary commerce students academic achievement based on Medium of Instruction.

ENGLISH : 1.2135

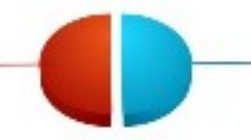

TAMIL : 1.1975

Figure 2:Relationship Between Students medium of instruction and Impact of Mobile Learning Among Higher Secondary Commerce Students Academic Achievement

\section{TESTING HYPOTHESIS 3:}

There will be a significant mean score differ-ence in impact of mobile learning among higher secondary commerce students academic achieve-ment based on School type (Government/Private).

TABLE 1.5 Mean Score difference and t- value of factors related to impact of mobile learning among higher secondary commerce students academic achievement based on School type

(Government/Private).

\begin{tabular}{|c|c|c|c|c|c|c|}
\hline $\begin{array}{c}\text { S. } \\
\text { No. }\end{array}$ & $\begin{array}{c}\text { School } \\
\text { Type }\end{array}$ & $\mathrm{N}$ & Mean & Df & $\begin{array}{c}\text { T- } \\
\text { Value }\end{array}$ & Result \\
\cline { 1 - 5 } 1 & $\begin{array}{c}\text { Govern } \\
\text { ment }\end{array}$ & 161 & 1.2283 & \multirow{2}{*}{299} & 0.908 & Ns \\
\cline { 1 - 5 } 2 & Private & 139 & 1.1987 & & \\
\hline \multicolumn{2}{|c|}{ Total } & 300 & 1.2135 & & \\
\hline
\end{tabular}

The Table 1.6 shows the mean score dif-ference in impact of mobile learning among higher secondary commerce students academic achievement based on School Location (Ru-ral/Urban). The calculate $t$ value is statistically a significance at 0.05 levels and hence the hypothe-ses 4 is accepted. It can be concluded that there is a significant difference in mean score difference in impact of mobile learning among higher secondary commerce students academic achieve-ment based on Location (Rural/Urban). 


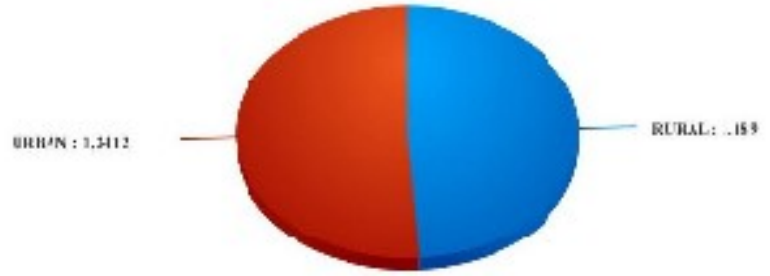

Figure4.3: Relationship Between Students school location and Impact of Mobile Learning Among Higher Secondary Commerce Students Academic Achievement

\section{FINDINGS OF THE STUDY}

$>$ There is a significant relationship between gender and impact of mobile learning among higher secondary commerce students academic achievement.

$>$ There is a significant relationship between medium of instruction related factors and impact of mobile learning among higher secondary commerce students academic achievement.

$>$ There is no significant relationship between school type related factors and impact of mobile learning among higher secondary commerce students academic achievement.

$>$ There is a significant relationship between school location and impact of mobile learning among higher secondary commerce students academic achievement.

\section{SUMMARY}

$>$ A study of mobile learning and its impact on academic achievement among higher secondary commerce students was studied and the findings reveal that there is a significant difference between impact of mobile learning among higher secondary commerce students academic achievement with respect to gender, Medium of instruction and School location.

$>$ A study of mobile learning and its impact on academic achievement among higher secondary commerce students was studied and the findings reveal that there is no significant difference between impact of mobile learning among higher secondary commerce students academic achievement with respect to School type.

\section{LIMITATIONS}

$>$ The study has certain limitation, which are as follows:

$>$ Only 712 students are selected as sampling for the study.
$>$ The project has been restricted to analyze and study in mobile learning and its impact on academic achievement among higher secondary commerce students.

$>$ The study is restricted to the school students of Coimbatore.

\section{CONCLUSION AND FUTURE RECOMMENDATIONS}

$>$ A Similar Study can be conducted for dissertation by taking more number of concepts and students.

$>$ The study can be conducted to other schools around Tamilnadu.

$>$ Present survey helps to investigate the impact level of higher secondary commerce students.

A similar study can also be conducted using various variables.

The conclusion is that there is a significant relationship between gender, medium of instruction and school location on impact of mobile learning among higher secondary school commerce students. While taking decision on impact of mobile learning among higher secondary school commerce students their school location and medium of instruction has to be taken for decision making process.

\section{BIBLIOGRAPHY}

1. Agarwal, Anmol, et al. (2014): Mobile application development with augmented reality. International Journal of Computer Science International Journal of Computer Sciences and Engineering and Engineering 2: 20-25.

2. Alexander, Bryan. (2004): Going nomadic: Mobile learning in higher education. Educause review 39.5: 28-34.

3. Banerjee, Sashwati, et al.(2018): Can Digital Technologies Play a Role in Improving Childrens Learning Outcomes in India?. Journal of Development Policy and Practice : 2455133317736234.

4. Bannan, Brenda, John Cook, and Norbert Pachler.(2016): Reconceptualizing design research in the age of mobile learning. Interactive Learning Environments 24.5 : 938-953.

5. Bano, Muneera, et al. (2018): Mobile learning for science and mathematics school education: A systematic review of empirical evidence. Computers \& Education. 
6. Baran, Evrim.(2014): A review of research on mobile learning in teacher education. Journal of Educational Technology \& Society 17.4: 17.

7. Boticki, Ivica, et al. (2015): Usage of a mobile social learning platform with virtual badgesin a primary school. Computers \& Education 86120136.

8. Chen, Gwo-Dong,Chih-Kai Chang, and Chih-Yeh Wang. (2008): Ubiquitous learning website: Scaffold learners by mobile devices with information-aware techniques. Computers \& education 50.1 77-90.

9. Chen, Yuh-Shyan, Tai-Chien Kao, and JayPing Sheu.(2003): A mobile learning system for scaffolding bird watching learning. Journal of Computer Assisted Learning 19.3 347-359.

10. Crompton, Helen, and Diane Burke.(2017): Research trends in the use of mobile learning in mathematics. Blended Learning: Concepts, Methodologies, Tools, and Applications. IGI Global,. 2090-2104.

11. Efstathiou, Irene, Eleni A. Kyza, and Yiannis Georgiou.(2018): An inquiry-based augmented reality mobile learning approach $n C$ to fostering primary school students historical reasoning in non-formal settings. Interactive Learning Environments 26.1 22-41.

12. Huang, Chester SJ, et al. (2016): Effects of situated mobile learning approach on learning motivation and performance of EFL students. Journal of Educational Technology \& Society 19.1263.

13. Huang, YuehMin, and PoSheng Chiu.(2015): The effectiveness of a meaningful learningbased evaluation model for contextaware mobile learn- ing. British Journal of Educational Technology 46.2 437-447.

14. Reeves, Jennifer L., Glenda A. Gunter, and Candace Lacey. (2017):Mobile Learning in PreKindergarten: Using Student Feedback to Inform Practice. Educational Technology \& Society 20.1 37-44.

15. Sharples, Mike, Dan Corlett, and Oliver Westmancott.(2002): The design and implementation of a mobile learning resource. Personal and Ubiquitous computing 6.3 220-234.

16. Sharples, Mike, Josie Taylor, and Giasemi Vavoula. (2010):A theory of learning for the mobile age. Medienbildung in neuen Kulturrumen. VS Verlag fr Sozialwissenschaften, 87-99.

17. Singh, K. P., and Malkeet Singh Gill.(2015): Role and users approach to social networking sites (SNSs): a study of universities of North India. The Electronic Library 33.1 19-34.

18. Traxler, John. Current state of mobile learning.(2009): Mobile learning: Transforming the delivery of education and training 19-24.

19. West, Darrell M. (2013): Mobile learning: Transforming education, engaging students, and improving outcomes. Brookings Policy Report 17.

\section{APPENDICES \\ PROFORMA FOR BASIC DATA}

1. Name of the Student:

2. Name of the School:

3. Gender $\longrightarrow$ : Male $\square$ Female $\square$

4. Medium of

Instruction $\longrightarrow$ :Tamil $\square$ English $\square$

5. School Type $\quad$ : Govt $\square$ Private

6. School Location : Rural $\square$ Urban 
International Journal of Trend in Scientific Research and Development (IJTSRD) ISSN: 2456-6470

\begin{tabular}{|c|c|c|c|}
\hline S. & Question & \multicolumn{2}{|c|}{ Answer } \\
\hline 1 & In your view, has mobile ever used for education? & Yes & No \\
\hline 2 & Has mobile ever used for the education of any of your family or friends? & Yes & No \\
\hline 3 & Apart from mobile education, are you aware of E- Learning? & Yes & No \\
\hline 4 & Do you feel the way of learning is generally changing in recent years? & Yes & No \\
\hline 5 & Have you heard of " MOOC courses"? & Yes & No \\
\hline 6 & $\begin{array}{l}\text { Do you think MOOC coursesis something that is helping or is going to improve, } \\
\text { Personally? }\end{array}$ & Yes & No \\
\hline 7 & Do you think anything can be done to improve MOOC Courses quality? & Yes & No \\
\hline 8 & Have your ever taken, or do you regularly take, any steps for mobile learning? & Yes & No \\
\hline 9 & Is Schools already following mobile learning? & Yes & No \\
\hline 10 & Is there anything mobile learning help us in Knowledge gaining? & Yes & No \\
\hline 11 & Will learn through mobile be affect our economy? & Yes & No \\
\hline 12 & Would a Mobile learning of Commerce subject really change the understanding level? & Yes & No \\
\hline 13 & Are MOOC courses taught more than teachers? & Yes & No \\
\hline 14 & Can Mobile learning really essentials for school students in future? & Yes & No \\
\hline 15 & Can Mobile learning lead to Globalization education? & Yes & No \\
\hline 16 & Will Mobile learning actually bring obstruction to some students? & Yes & No \\
\hline 17 & Could mobile learning ever" Come to no good"? & Yes & No \\
\hline 18 & Have the Knowledge from mobile learning useful in exams? & Yes & No \\
\hline 19 & Is there formal way of mobile learning is under way? & Yes & No \\
\hline 20 & Are you concerned about mobile learning? & Yes & No \\
\hline 21 & Are you aware of the impacts of mobile learning? & Yes & No \\
\hline 22 & Are you aware of the causes and effects of mobile learning? ntific & Yes & No \\
\hline 23 & Do Students also share their learning with others through mobile learning? & Yes & No \\
\hline 24 & Couldn't the usage of technology cause the mobile learning? & Yes & No \\
\hline 25 & Don't students learn more ideas from mobile learning than textbooks? & Yes & No \\
\hline 26 & Hasn't education system improved or demoted after mobile learning implementation? & Yes & No \\
\hline 27 & Are there positive benefits from mobile learning? & Yes & No \\
\hline 28 & Can we pay additional fee for mobile learning? $00=04 / 0$ & Yes & No \\
\hline 29 & Are practical sessions are missed in mobile learning? & Yes & No \\
\hline 30 & Will mobile learning cause the limited learning opportunities? & Yes & No \\
\hline
\end{tabular}

